\title{
19
}

\section{MA in Participation, power and social change at University of Sussex}

\author{
Felix M. Bivens
}

\section{Context}

The MA in Participation (MAP) had its first intake of students in 2004. MAP is the product of several years of planning and more years of previous work by the Participation, Power and Social Change (PPSC) team at Institute of Development Studies (IDS), University of Sussex. The roots of PPSC connect to the highly influential work of Robert Chambers in the field of participatory development. In the 1990s, his books, including Whose Reality Counts? Putting the First Last (1997), helped to precipitate a sea change in international development thinking towards participatory, 'bottom up' development practices driven by local community planning and the daily realities of the poor.

IDS itself has been a training hub for development specialists for decades. Affiliated with the University of Sussex in Brighton, IDS is able to award MA and D.Phil. degrees in the field of development studies. Many of the students who came to IDS for their graduate training were drawn by Chambers's reputation and this discourse on participatory development. However, PPSC had no teaching programme. As more students sought out PPSC team members for advice and independent research supervision, the idea developed to create an MA programme which focused specifically on participatory development. Another frequent complaint among students at IDS was that their own experience as development practitioners was not recognized or utilized in MA programmes. As many IDS students were from developing countries and/or had multiple years of professional experience in NGOs or government ministries, they were frustrated that there was little opportunity to share, reflect and make sense of their own experiences. This also struck a chord with PPSC members whose work was premised on recognizing and elevating contextualized, experiential knowledge as equally valid to elite knowledge from universities and other institutions. Thus, the proposed PPSC MA programme was understood to be a space not only for sharing the research of the participation team but for allowing students to share, explore and deepen their own understandings as practitioners within their unique contexts.

According to Peter Taylor, the first convener of MAP:

This Master's degree aims to provide structured educational opportunities to deepen knowledge and practice of participatory approaches for engaging people in decision- 
making and active citizenship in a range of diverse contexts; foster innovations in the theory, practice and methodologies of participation, development and social change through participatory research, critical reflection and analysis; and contribute to the development, dissemination and institutionalization of high-quality participatory practices and processes globally through the work of students, alumni and a variety of partnerships with individuals and institutions worldwide. It is grounded in a process of critical reflection on experience and combines residential intensivestudy periods with a longer period of action research in a work-based placement. (2008, p. 366)

The course turns on the concept of praxis. The basic premise is that experienced practitioners and activists come to IDS for one residential term (ten weeks), on a short leave of absence from work organizations. In this time they explore their own experiences in relation to a broad body of literature and concepts related to participation. Students also devise a PAR plan to be carried out back in their home contexts that would allow them to explore actively these new ideas and methods. At the end of the term, students return to their organizations and carry out their action research projects for one year in the field, coming back together once during that period to share and reflect. After that year, the programme reconvenes at IDS for a final term of reflection and for writing analysis papers which allow MAP students to synthesis theory and experience across the full eighteen months of the programme.

Because of the emphasis on allowing students to remain grounded in their work contexts, MAP diverges from other IDS MA programmes which run for one calendar year, with students residential for most of that period. Thus, development practitioners heavily engaged in their work and careers were often deterred from pursing an MA at IDS because it required leaves of absence from their jobs. As a result, such MA programmes often draw younger development workers with sometimes only a few years of relevant experience. MAP raised the bar by setting a prerequisite of five years of development work experience as well as requiring a predetermined professional or community context in which the fieldwork portion of the course would be carried out. As such, the programme was able to attract students with extensive development backgrounds. This helped to ensure the dialogical nature of the course, so that learning would be happening in multiple directions, from student to student, from student to teacher, and not simply from teacher to student. Although IDS was somewhat resistant to this structure initially, PPSC team members found a great deal of support and energy within the University of Sussex.

The curriculum for the first term of MAP has two courses, Foundations of Participation, and Ideas in Development. The Ideas in Development is an IDS-wide seminar series, compulsory for all students. It draws upon academics from across different IDS areas of research at IDS; students are exposed to diverse perspectives and current research on many different topics within the development field. Foundations of Participation, on the other hand, is designed for and open only to MAP students. It is basically two courses in one, divided into two distinct streams: (1) Action Research and Reflective Practice; and (2) Power, Participation 
and Social Change. The second stream is more traditionally academic. It covers the epistemological and methodological issues at the core of the participatory development paradigm. This part aims to provide a grounding in concepts and theories for understanding and shaping social change and to influence development policy and practice. We introduce theory as a lens to illuminate pathways for action, and explore concepts and processes with case studies developed by the participants, drawing on their own experience.

The course is team taught across the whole of the PPSC team so that each week MAP students engage with a different research Fellow. Fellows share their experiences and current research, looking for resonance with the experiences of the MAP students.

The Action Research/ Reflective Practice stream is less conventional in its structure and is key to what makes MAP an innovative programme, curricularly and pedagogically. Originally, the stream had a strict focus on action research and in helping students conceptualize their fieldwork projects. Over time, however, it has evolved into two distinct components as the reflective practice element of MAP has become more pronounced. In fact, the action research and reflective practice components occur as two different class meetings each week, each stream with its own facilitator who works intensively with the students throughout the whole of the MA programme. The weekly action research meeting functions like a 'homeroom' for MAP students. It is facilitated by the course convener and is the primary space for determining the direction of the course from week to week. Each meeting usually begins with a feedback session, where participants reflect and discuss what they have benefited from and learned in terms of lectures and workshops. They assess the quality and relevance of assigned readings and discuss points they feel need further clarification.

From this, the discussion moves to where the group feels they want the course to take them next. In this respect, the course attempts to adhere to a process of participatory curriculum development. Against a backdrop of developing their PAR projects and of writing a concept paper that lays out the historical background of the context and the proposed methodological structure of their research, MAP students are constantly perceiving gaps in their knowledge and discovering new concepts and methods to explore further. The group cooperatively sets the agenda for their next meeting. They may agree to bring in a speaker with a specific expertise, or to hold a methods bazaar where they share participatory methods they have had experienced, or they may decide to give presentations about their tentative PAR projects, for feedback. Once a plan has been set for the next class meeting, the group will carry out the particular set of activities laid out the previous week. Thus, the content of these class meetings is emergent and co-produced by the cohort. Although a great deal of energy is devoted in this space to what they will do in the course, students also become acutely aware of how things are done. There is an intensive focus on process. In the original concept note for the MAP programme, PPSC members wrote, 'The process is the content'. They see how they work with each other as a measure of how they are progressing as facilitators of multi-stakeholder participatory processes. 
While the action research meeting functions loosely to help students to move forward with their academic and research assignments, the reflective practice element of the course is largely delinked from the academic push of the programme. Rather than a focus on doing, here the focus is on being. The aim of the inquiry is not the work but the individual, not the professional, but the personal. There are still assigned readings and assignments, but the thrust is quite different. The aim is for students to become more self-aware and analytical of themselves as development practitioners.

Throughout the stream, students will learn and practice methods of reflective practice, both for personal inquiry within action research processes, and for methods for developing reflexivity within one's ongoing work with organizations, communities and other actors. There will be an emphasis on techniques of creative and reflective writing, journalling and auto-ethnography that students can use to understand and position themselves within their research and practice, and to develop and express their findings. We will explore issues of identity, values, knowledge and belief systems, and the way these influence behaviour and interventions, and shape the researcher's action, interpretations and data analysis (Institute of Development Studies, 2008).

This course element is focused on students' experiences and in helping them to make sense of where they have been as a means to seeing where they want to go. Although all programme aspects feed heavily on participants' professional experiences, reflective practice encourages students to look into their own lives and histories to uncover motivations, biases and tacit assumptions that shape and potentially inhabit their thinking. As a result, much of the work in the class is done through journalling and creating narratives. Deepening reflexivity, the students hold a mirror up to themselves as change agents to consider if making change is sometimes contingent on changing themselves first.

The work in these sessions is often collective as well as individual. Students share their creative work and frequently they engage in active techniques for exploring complex issues. If discussing ideas of embodied power, students may act out situations using 'theatre of the oppressed' methods to help them experience and imagine different ways of relating and working with others. Although bringing MAP students' experiential knowledge into the learning process was always an aim of MAP, the reflective practice stream of the programme has become more prominent over time, starting as a workshop in the later part of the first cohort, but received so enthusiastically it became a stream running throughout the whole programme.

At the close of the first term of MAP, participants submit two written papers: an analytical paper looking at the question they will address in their fieldwork from a theoretical and conceptual perspective, asking them to interrogate their professional experience with their newly acquired academic perspectives as lenses. Students also submit a learning process and plan which lays out the strategy for their year-long PAR project. Around this time, MAP participants choose an IDS Fellow who will supervise their field research and subsequent dissertation. Although students generally choose PPSC Fellows, they can choose any Fellow in IDS willing to support them over the next fifteen months of the programme. 
For the next six months, students work independently in their home contexts and organizations. They dialogue periodically with their research supervisors and the course convener and submit quarterly reports about their research progress. In June, they reassemble at IDS for a mid-placement seminar to report on their work and spend time engaged in further desktop research. Each student leads a seminar about their work and receives feedback from fellow students, supervisors and other PPSC researchers. Much of the focus of class meetings outside of student seminars is around the challenges and complexities of facilitating PAR processes. Because of the emergent, collective nature of PAR, MAP students often find themselves diverging from their learning plans and following the energy of the situation in new directions. Much of the discussion is around how students can reconnoitre these new situations.

Students then head back to the field for another six months. This middle portion of the programme is assessed by a reflective essay in which students chronicle the personal experience of their research and inquire into their own transformation. This is submitted upon their return to IDS for the final term, along with a portfolio which can contain diverse artefacts - photographs, maps, poems, etc. - which augment the student's personal written reflective.

The final term of MAP concentrates on synthesis. Students continue to meet weekly with the course convener, developing the content and aims of these meetings in a participatory style as before, meeting at times with their reflective practice facilitator. They take one regular academic course from the IDS catalogue, but the majority of the term is spent in independent study as the participants prepare a 10,000-word dissertation which links their PAR fieldwork with the course's conceptual elements. Given the nature of PAR, the research projects are understood to be 'works-in-progress' that will continue to evolve after students have completed their studies with MAP.

\section{Curricular and pedagogical impacts of MAP}

Initially, MAP was slow to have a direct impact on the development of curriculum at IDS. There were two primary reasons for this. First, lecturers rarely sit in another teacher's class. Although the MAP programme was pushing boundaries at IDS with new participatory pedagogies, few outside of the PPSC team had enough contact with the programme to see what was happening in the classroom. Further, the original timing of the MA in Participation course was out of sync with other IDS teaching programmes. Rather than beginning in October, as it does now, the first two iterations of MAP began in the summer when other MA programmes were on break. While this gave MAP students more access to resources like seminar rooms, it meant they had no opportunity to engage with other MAs, partake of seminars and lectures from other research areas, or take part in the social life of IDS. Once MAP was rescheduled to fall in rhythm with the rest of IDS's teaching calendar, it immediately began to attract the attention of other MA students because MAP students were now in class with these students. Recalled former MAP convener Peter Taylor: 
I remember last year in the Ideas in Development sessions when each group of students did a short feedback in the Ideas lecture - the participation students at the time did the most innovative and dramatic presentation and it 'knocked everybody for six' including the lecturer. And it's those moments when other students and staff have been exposed to MAP students that they really realize that there is actually something quite unusual and different here which - when people experience it in some way for themselves - it gets them to reflect a little bit on their own teaching. (2008, p. 12)

It was through such in-class interactions that students and lecturers outside of MAP began to see the distinct approach at work. There was particularly strong student interest in the reflective practice dimension of MAP. Sensing this energy, PPSC Fellow Jethro Pettit introduced a stand-alone reflective practice course open to all IDS participants. In its first offering, it became the second-most subscribedto course in the Institute. Students were hungry for the opportunity to make sense of their own experiences as practitioners and to not just take on new ideas and information. The course quickly created ripples more widely across the Institute. Non-MAP students who had taken the reflective practice offering approached their course conveners about utilizing reflective concepts and methods in final dissertations. Some conveners agreed and were quite pleased with the quality of those dissertations. The following academic year, the convener of the MA in poverty and vulnerability decided to add a reflective practice stream to that programme. He explained his motivations as such, in an interview (2009):

I didn't know exactly was I getting. Wasn't clear. It was only at the end of term that I got some sense. I was understanding it as something that would contribute to the learning experience of students - and it for sure has done that. I'm just amazed at how well received it's been ... A programme in which the agenda is to be determined through classroom processes, which Sarah [MAP's reflective practice facilitator] is extremely good at. So there's a joined-up collective process by which learning needs are prioritized. For example, in the second term they just started with meetings and the agenda emerged from that ... Having this alternative understanding of what the learning experience is about can only do us good. And if, at the same time, it's directly contributing to each individual student's learning experience - seems like a winner all around.

The following academic year, the MA in gender and development added sessions in reflective practice. Three of IDS's eight MA programmes now included an embedded reflective practice stream, as well as the stand-alone reflective practice course open to all students, including D.Phil. students.

Working with MAP and the reflective practice course also encouraged PPSC fellows to develop a new course for all students. The revamped Empowering Society course is a compact mixture of several pedagogical elements field tested in MAP. It is facilitated with a participatory, dialogical pedagogy in which the direction of the class meetings is determined by class members. Moreover, the course offers students the opportunity to engage in CBR. The course turns around a PAR project in the local Brighton community. Students from the module divide into small teams and take on a variety of CBR inquiries around the city. Such 
projects have included working with immigrant taxi drivers, revitalizing a local shopkeepers' association and organizing a campaign to stop a large grocery chain from opening on a high street populated with mom-and-pop grocers. Although the time-frame for the projects was quite limited - only ten weeks - students were successful in drawing attention to their issues through newspaper articles and $\mathrm{BBC}$ radio. This experience cemented the Empowering Society course as an opportunity for IDS students to engage with local issues and build relationships in the community. Moreover, it was the first course at IDS in which students received academic credit for CBR projects. 